\title{
DIREITOS HUMANOS SOB FOGO CRUZADO: INJUSTIÇA AMBIENTAL, RACISMO, SEXISMO E CLASSES SOCIAIS
}

\author{
HUMAN RIGHTS UNDER CROSSFIRE: \\ ENVIRONMENTAL INJUSTICE, RACISM, SEXISM AND SOCIAL CLASSES
}

\author{
Sávio SILVA DE ALMEIDA \\ Mestre em Desenvolvimento e Meio Ambiente - PROdema/UfPe (Área de Concentração: Gestão e Políticas \\ AMBIENTAIS). PROFESSOR UNIVERSITÁRIO. \\ savio_eco@hotmail.com
}

Mônica CoX de BRItTo Pereira

Doutora em Ciências Socials. Professora dos Programas de Pós-Graduação em Desenvolvimento e Meio Ambiente e

GEOGRAFIA DA UFPE. coxmonica@gmail.com

\begin{abstract}
RESUMO
O objeto estudado é a ameaça aos direitos humanos, que se sustenta em aspectos culturais (racismo e sexismo) e de desigualdade (injustiça ambiental e desigualdade de classes). Partindo da preocupação acerca da 'naturalização' da discriminação, que constrói: o 'outro', a 'natureza', as 'hierarquias' sociais e os 'colonialismos', que tomam a forma de exclusões - racismo, sexismo -, desigualdades de classes e injustiça ambiental. Desta maneira, o presente artigo possui o objetivo de analisar como as doutrinas acerca da exclusão e da desigualdade favorecem as violações de direitos humanos. Para tanto, foi realizada extensa revisão bibliográfica acerca do objeto estudado. Chegou-se a conclusão de que gênero, raça, injustiça ambiental e desigualdade de classes são construções sociais que se alinham para o enfraquecimento da relevância da construção sociohistórica dos direitos humanos.
\end{abstract}

Palavras-chave: Colonialismo; Desigualdade; Direitos; Exclusão.

\begin{abstract}
The object studied is the threat to human rights, which is based on cultural aspects (racism and sexism) and inequality (environmental injustice and inequality of classes). Starting from the concern about the "naturalization" of discrimination, which builds: the 'other', the 'nature', the 'hierarchies' social and 'colonialism', which take the form of exclusions racism, sexism - class inequalities and environmental injustice. Thus, the present article has the objective to analyze how the doctrines of exclusion and inequality favor human rights violations. Therefore, extensive literature review was carried out about the studied object. The conclusion that gender has come up, race, environmental injustice and class inequality are social constructs that align to the weakening of the relevance of socio-historical construction of human rights.
\end{abstract}

Keywords: Colonialism; Exclusion; Inequality; Rights. 


\section{SUMÁRIO}

INTRODUÇAO; 1 DIREITOS - E - HUMANOS ENTRE A DESIGUALDADE E A EXCLUSÃO; 2 DIREITOS HUMANOS E A INJUSTIÇA AMBIENTAL; 3 DIREITOS HUMANOS E RACISMO; 4 DIREITOS HUMANOS E SEXISMO; 5 DESIGUALDADE DE CLASSES, DIREITOS DESIGUAIS; CONCLUSÃO; REFERÊNCIAS.

\section{INTRODUÇÃO}

O presente trabalho aborda a problemática acerca dos critérios de exclusão e desigualdade que fundamentam as violações de direitos humanos. Dentre os critérios de exclusão, o presente trabalho discute duas questões fundamentais, tais como o racismo e o sexismo. Quanto aos critérios de desigualdade, são trabalhadas a injustiça ambiental e a desigualdade de classes.

No capítulo 2, Direitos - e - Humanos entre a Desigualdade e a Exclusão, o entrelaçamento entre os critérios de exclusão e desigualdade, sob a modernidade/colonialidade capitalista são desvendados, demonstrando como a face colonial da modernidade capitalista ainda, nos dias hodiernos, se faz presente.

No capítulo 3, Direitos Humanos e Injustiça Ambiental, o foco recai especificamente na injustiça ambiental como violação dos direitos humanos, ressaltando como tal violação recai de forma desproporcional sobre grupos minoritários, ou seja, como tal injustiça, por exemplo, recai sobre determinados grupos étnico-raciais e a classe trabalhadora.

No capítulo 4, Direitos Humanos e Racismo, a atenção se volta para um dos critérios de exclusão mais devastadores já produzido pela modernidade capitalista, o critério racial. 0 capítulo 4 ressalta que as relações raciais não possuem fundamneto biológico, mas trata-se de um critério político, historicamente, construído em torno da cor da pele para legitimar a exploração/exclusão de determinados grupos humanos, sendo, por isso, funcional ao sistema capitalista, como sua lógica cultural eurocentrada.

No capítulo 5, Direitos Humanos e Sexismo, debate-se acerca de como às Mulheres tem sido imposta uma lógica cultural de exclusão, uma lógica que as inferioriza por serem justamente as responsáveis pela criação da vida, privilegiando a "masculinidade", enquanto “dominadora” e responsável pela destruição da vida. 
DIREITOS HUMANOS SOB FOGO CRUZADO: INJUSTIÇA AMBIENTAL, RACISMO, SEXISMO E CLASSES SOCIAIS SÁVIO SILVA DE ALMEIDA MÔNICA COX DE BRITTO PEREIRA

No capítulo 6, Desigualdades de Classes, Direitos Desiguais, além do reconhecimento da relação desigual capital-trabalho, é vislumbrada como as demais exclusões e desigualdades são funcionais à reprodução do sistema capitalista.

0 trabalho conclui, portanto, que as exclusões (racismo e sexismo) e que as desigualdades (injustiça ambiental e classes sociais) não são autoexcludentes, mas que se somam no processo de aniquilação da dignidade humana, que é o processo de violação de todos os direitos humanos.

Trata-se, assim, de uma pesquisa qualitativa, descritiva e que se baseou em extensa revisão bibliográfica acerca do tema proposto. 0 presente artigo possui o objetivo de analisar como as doutrinas acerca da exclusão e da desigualdade favorecem as violações de direitos humanos.

Compreende-se no presente trabalho que a realidade é complexa e não linear. De acordo com Demo (2009) quando aplicada à realidade, a noção de complexidade realça as seguintes dimensões cruciais: a) imprecisão: a realidade é imprecisa; b) criatividade: a realidade é criativa; c) indevassabilidade: a realidade é indevassável e as teorias são ensaios aproximativos e provisórios; d) historicidade: a realidade é histórica, e assim sendo é também irreversível, no sentido de que a trajetória evolucionária da realidade não pode ser reduzida a replicação das estruturas, mas ao contrário tal trajetória implica em uma criatividade exuberante; e) potencialidade: a realidade é potencial, no sentido de que a mesma possui dinâmicas que ultrapassam os seus pontos de partida, seria como se a realidade não coubesse nela mesma.

A noção de imprecisão ressalta que a ideia da imposição global de uma única noção de direitos humanos é por demais formal-linear, por isso incapaz de captar a ambiguidade e a ambivalência da realidade. A noção da criatividade contida na realidade ressalta a noção acerca da possibilidade do salto emergente dos direitos humanos, para além da concepção única de direitos, que serve ao projeto político-ideológico do capital. A noção da indevassabilidade do real ressalta que os direitos humanos tal como inscritos são apenas noções aproximativas do ideal, por isso devido às novas faces da realidade que vão aos poucos surgindo é possível inscrever os direitos humanos, sobretudo, os direitos sociais e econômicos, em termos de luta de classes, pois só assim os mesmos podem ser mais coerentes com a noção da dialética. A noção da historicidade do real aponta que a história dos direitos humanos ainda está sendo escrita. A noção da potencialidade do real ressalta que os direitos humanos como direitos muitas vezes violados e servis ao projeto do capital, podem ser reconstruídos e assumir dinâmicas que 
ultrapassem os pontos de partida originais, para que se tornem representantes do projeto da dignidade humana, tal como descrito na Declaração Universal dos Direitos Humanos, de 1948.

\section{DIREITOS - E - HUMANOS ENTRE A DESIGUALDADE E A EXCLUSÃO}

A Declaração Universal dos Direitos Humanos, da ONU, não oferece nenhuma proteção contra resultados desiguais, o que permite que a distinção entre direitos civis e políticos, por um lado, e direitos econômicos e sociais, por outro lado, torne-se um campo de contestações e reivindicações. Como a desigualdade de classes é central para a própria reprodução do capitalismo, o poder político ou nega que as classes existem ou afirma que a categoria 'classes' é tão confusa e complicada que acaba por tornar-se analiticamente inútil - como se outras categorias como gênero e raça não fossem complicadas e confusas -. Contudo, claramente, as identidades de classe, bem como as identidades raciais, são múltiplas e sobrepostas (HARVEY, 2011). Para Harvey (2012a, p. 137): “Distinções de classe, de raça, de gênero e de uma multiplicidade de outros aspectos se acham inscritas no corpo humano em virtude dos diferentes processos socioecológicos que exercem sua ação sobre esse corpo".

0 processo de globalização traz em si a globalização das formas de exploração da natureza com rejeitos e proveitos distribuídos desigualmente - injustiça ambiental -. Há, junto com o processo de globalização, a dominação da natureza e a dominação de alguns homens por outros homens, da cultura europeia sobre outros povos e outras culturas, e dos homens sobre as Mulheres. Houve argumentos, em demasia, apontando que tal dominação se dava por razões naturais, na medida em que certas raças seriam naturalmente inferiores. A modernidade europeia inventou a racialidade - base da escravidão moderna - e a colonialidade; então, essa tríade - modernidade-colonialidade-racialidade - continua atravessando, mesmo nos dias atuais, as práticas de poder e sociais (PORTO-GONÇALVES, 2013).

Os elementos raça e divisão do trabalho, muito embora nenhum dos dois seja dependente do outro para transformar-se ou existir, foram estruturalmente associados, reforçando-se mutuamente (QUIJANO, 2005). É no século XIX que melhor se podem analisar os sistemas de desigualdade e de exclusão, uma vez que é neste século que se consuma a convergência da modernidade e do capitalismo. 0 grande teorizador da desigualdade moderna capitalista é Karl Marx, para quem a relação capital/trabalho é o grande princípio da integração social na sociedade capitalista, uma integração assentada na desigualdade entre trabalho e capital, uma 
DIREITOS HUMANOS SOB FOGO CRUZADO: INJUSTIÇA AMBIENTAL, RACISMO, SEXISMO E CLASSES SOCIAIS SÁVIO SILVA DE ALMEIDA MÔNICA COX DE BRITTO PEREIRA

desigualdade classista que se baseia na exploração. Michel Foucault, por sua vez, é o grande teorizador da exclusão. A desigualdade é um fenômeno socioeconômico, porém a exclusão é, sobretudo, um fenômeno sociocultural, um fenômeno civilizatório. A exclusão é um processo histórico através do qual uma cultura cria o interdito e o rejeita, por via de um discurso de verdade. Sendo cultural e civilizacional, a exclusão causa impactos socioeconômicos. Racismo e sexismo são dispositivos de hierarquização que combinam a exclusão de Foucault e a desigualdade de Marx¹ (SANTOS, 2010).

No momento em que se tornou intimamente entrelaçado com a etnicidade, o nacionalismo atuou dando uma ênfase cada vez maior nas explicações biológicas para a diferença. Uma vez que os argumentos para os direitos humanos tinham se baseado na pressuposição da igualdade da natureza humana em todas as classes e culturas, depois da Revolução Francesa, tornou-se mais difícil reafirmar as diferenças com base nos costumes, na história ou na tradição. Dever-se-ia encontrar um fundamento mais sólido para que fosse mantida a hierarquia superior dos homens em relação às Mulheres, dos cristãos em relação aos judeus, dos brancos em relação aos Negros. O século XIX presenciou muitas explicações biológicas acerca da diferença, pois se os direitos deviam ser menos que naturais, iguais e universais, era necessário explicar o motivo para tal afirmação (HUNT, 2009).

A despeito do proclamado "reconhecimento" da dignidade humana havia uma crua ontologia da desumanização axiológica da maioria dos seres humanos, na tradição liberal, que tinha seu cerne na recusa de conceber o homem como ser genérico-universal. Tal recusa permitia aceitar como "natural” a situação de inferioridade da Mulher; compreender como "natural" a interdição dos direitos políticos e civis aos pobres; "natural" a recusa de quase todos os direitos aos povos colonizados, bem como "natural" a recusa de todos os direitos aos escravos. Mais tarde, após recolher todo o veneno destilado pelos liberais, os nazistas lhe dariam um seguimento logicamente perfeito ao desdobrá-lo em uma antropologia do descarte, solução "final" que estendeu a desumanização aos comunistas e outros opositores políticos, às raças “inferiores", aos doentes mentais, aos homossexuais et allii (TRINDADE, J., 2011).

$\mathrm{Na}$ realidade, os preconceitos, as instituições e as culturas pré-capitalistas são revolucionados, apenas, no sentido de receberem novos significados e funções, em vez de serem destruídos. Tal afirmação é tão verdadeira em relação a preconceitos, como sexismo, tribalismo e racismo, quanto o são em relação a instituições, como a lei e a igreja. Tais diferenciações nos

\footnotetext{
${ }^{1}$ Florestan Fernandes (2008), por exemplo, trouxe à luz contribuições relevantes acerca da discriminação racial na sociedade brasileira, a partir da análise da desigualdade.
} 
DIREITOS HUMANOS SOB FOGO CRUZADO: INJUSTICCA AMBIENTAL, RACISMO, SEXISMO E CLASSES SOCIAIS SÁVIO SILVA DE ALMEIDA MÔNICA COX DE BRITTO PEREIRA

arranjos sociais e institucionais terminam por parecer o que realmente não são: apresentam-se como meros residuais históricos, quando são aspectos reconstruídos ativamente dentro do modo de produção capitalista (HARVEY, 2013). Assim é que a concepção católica de mundo, que foi característica do feudalismo, ao não mais satisfazer às respectivas condições de troca e produção e à classe burguesa, é substituída pela nova concepção de mundo, que se tornara clássica para a burguesia, a concepção jurídica de mundo. Tratava-se, de fato, da secularização da visão teológica. A Igreja era substituída pelo Estado, e o direito divino e o dogma pelo direito humano. As relações sociais e econômicas, que anteriormente eram representadas como criações da Igreja e do dogma, porque a Igreja as sancionava, passam a ser representadas como criadas pelo estado e fundadas no direito (ENGELS; KAUTSKY, 2012). Porém, “[...] a própria noção de direitos humanos abriu inadvertidamente a porta para formas mais virulentas de sexismo, racismo e antissemitismo" (HUNT, 2009, p. 188). De acordo com Mies (1993a, p. 239):

Foi fácil denunciar como fascista o genocídio na Alemanha de Hitler, mas poucas pessoas são capazes de discernir o genocídio que espreita sob a bandeira da eugenia; e menos ainda estão preparadas para denunciá-la publicamente como fascista. Existe, no entanto, uma continuidade histórica do movimento eugênico, via Alemanha nazi, até chegar às novas tecnologias reprodutivas: diagnóstico prénatal, engenharia genética, fertilização in vitro e outras afins. Os divulgadores e praticantes destas tecnologias fecham os olhos a esta herança histórica.

O sexismo, o racismo e o fascismo nem são desenvolvimentos recentes singulares nem são fenômenos universais fora do contexto da história, mas estão estreitamente ligados ao advento da ciência moderna e à expansão colonial da Europa. Foi na era do Iluminismo, nos séculos XVIII e XIX, que a distinção entre os Negros e mestiços como mais próximos da 'natureza', entre Mulheres e homens, e a população branca como 'humana' encontrou a sua mais clara expressão. Muitos políticos, filósofos e cientistas têm contribuído para a ideologia do sexismo e do racismo. Mesmo socialistas do século XIX partilhavam da visão segundo a qual os trabalhadores do mundo estariam divididos entre aqueles que pertencem às 'nações civilizadas' e aqueles que pertencem aos povos 'selvagens' ou 'nativos'. Por isso os sociais-democratas da Alemanha imperial, bem como os seus congêneres britânicos, opunham-se tão pouco ao colonialismo (MIES, 1993a). Para Mies (1993a, p. 236):

0 ponto central desses argumentos é a compreensão correta que as massas proletárias das nações civilizadas não seriam capazes de atingir um nível de vida mais elevado ou um nível cultural mais elevado, a menos que estas nações pudessem explorar livremente os territórios dos 'povos nativos' na procura de matérias-primas, mão de obra barata e mercados promissores. 
DIREITOS HUMANOS SOB FOGO CRUZADO: INJUSTIÇA AMBIENTAL, RACISMO, SEXISMO E CLASSES SOCIAIS SÁVIO SILVA DE ALMEIDA MÔNICA COX DE BRITTO PEREIRA

A universalidade dos direitos humanos sempre conviveu com a ideia de uma 'deficiência' originária da humanidade, a ideia de que nem todos os seres que possuem um fenótipo humano são plenamente humanos e por isso não deveriam beneficiar-se da dignidade e do estatuto conferidos à humanidade. Os preconceitos dominantes de natureza racista, sexista ou colonialista negavam as diferenças sexuais e étnico-culturais como formas próprias de pertença legítima a coletivos amplos e portadores da dignidade. Tal situação começa a sofrer abalos na estrutura do seu status quo quando os grupos sociais excluídos e discriminados se organizaram para lutar contra a exclusão e a discriminação, pondo em causa os critérios dominantes de diferença e igualdade e os diferentes tipos de exclusão e inclusão que legitimam (SANTOS, 2013). Para Vandana Shiva (2003, p. 21):

[...] o sistema dominante também é um sistema local, com sua base social em determinada cultura, classe e gênero. Não é universal em sentido epistemológico. É apenas versão globalizada de uma tradição local extremamente provinciana. Nascidos de uma cultura dominadora e colonizadora, os sistemas modernos de saber são, eles próprios, colonizadores.

É possível identificar na modernidade ocidental cinco monoculturas. A monocultura do conhecimento atribui privilégio absoluto primeiramente à teologia cristã e em seguida à ciência, tal processo significou a destruição de muitos conhecimentos e teologias, epistemicídio e teocídio, respectivamente; assim, os grupos cujas práticas se assentavam nos conhecimentos rivais aos hegemônicos foram declarados supersticiosos ou ignorantes. A segunda monocultura consiste em atribuir prioridade ética e cognitiva a entidades - princípios e valores “universalmente" válidas, a eleição de tais entidades ficou a cargo dos detentores de poder suficiente para transformar os seus interesses em situações gerais e ideais, desclassificando as demais entidades como simplesmente "particulares". A terceira monocultura é a do tempo linear, dotado de sentido e direções únicas: representado pela noção de progresso, de acordo com tal noção do tempo foi possível classificar arbitrariamente países, realidades e grupos sociais como ou avançados ou primitivos. A quarta monocultura é a das "hierarquias naturais" que consiste em distribuir as populações segundo hierarquias definidas por características sexuais e raciais. A quinta monocultura é a que trata a natureza e o trabalho como recursos produtivos potencialmente infinitos, assim, todas as demais formas de concepção acerca da natureza e do trabalho são descartadas como estéreis, improdutivas, etc. (SANTOS, 2008). Assim:

Estas cinco monoculturas produziram um vastíssimo conjunto de populações, formas de ser, de viver e de saber desclassificadas, segundo os casos, como ignorantes, inferiores, particulares, residuais, improdutivos. Não está em causa a 
DIREITOS HUMANOS SOB FOGO CRUZADO: INJUSTIÇA AMBIENTAL, RACISMO, SEXISMO E CLASSES SOCIAIS SÁVIO SILVA DE ALMEIDA MÔNICA COX DE BRITTO PEREIRA

existência de tais classificações, mas sim o modo como foram estabelecidas. 0 modo foi autoritário e sempre ao serviço de um projeto de dominação econômica, política, social e cultural (SANTOS, 2008, p. 1210).

A burguesia faz da dignidade pessoal um simples valor de troca, estabelecendo no lugar das inúmeras liberdades, uma vez, duramente, conquistadas, a implacável e única liberdade, a liberdade de comércio. No lugar da exploração que as ilusões religiosas e políticas mascaravam, a burguesia implantou uma exploração direta, brutal, aberta e despudorada. Até as relações familiares são reduzidas a simples relações monetárias (MARX; ENGELS, 2012).

Assim é que o mercado para alguns indivíduos é um critério adequado para a mensuração de sua própria auto-identidade, através de uma espécie de fetichismo de commodities, proclamando que 'eu sou o que eu posso comprar' ou 'eu sou o que eu possuo'. Porém, outras medidas de valor são muito importantes, também; tais como: status, posição social, prestígios e privilégios. Assim, temas que estão relacionados à base econômica da sociedade são frequentemente traduzidos em uma linguagem relacionada à posição social do grupo ao qual um determinado indivíduo pertence. Por exemplo, temas relacionados ao desemprego podem ser traduzidos em termos de discriminação étnica ou racial no mercado de trabalho (HARVEY, 2009). Bem como, temas como meio ambiente e gestão da água podem estar associados ao eurocentrismo, etnocentrismo e racismo (BERRY, 1998).

\section{DIREITOS HUMANOS E INJUSTIÇA AMBIENTAL}

O racismo ambiental, bem como a injustiça ambiental, destinada a grupos raciais discriminados, são conceitos que definem a situação de racismo institucional, vinculada à exposição a diversos riscos ambientais, a que determinados grupos raciais encontram-se submetidos. Muito embora não seja possível delimitar grupos raciais biologicamente, há estruturalmente uma construção sócio-histórica acerca da ideia de raça, mesmo que não seja possível encontrar uma definição universalmente válida para tal constructo social. A construção moderna-capitalista-colonial da ideia de raça tem causado resultados perversos, ao redor do globo, seja em termos de desigualdade, seja em termos de exclusão.

De acordo com Haesbaert e Porto-Gonçalves (2006, p. 48) uma pesquisa da ONU aponta que "[...] 32\% da população mundial [...] vive em favelas. Enquanto na Europa apenas 6,2\% da população é favelada, na América Latina são 31,9\% (127 milhões de pessoas) e na África Subsaariana são 71,9\% (166 milhões)". Segundo Mike Davis (2006) existe cerca de 200.000 favelas 
DIREITOS HUMANOS SOB FOGO CRUZADO: INJUSTIÇA AMBIENTAL, RACISMO, SEXISMO E CLASSES SOCIAIS SÁVIO SILVA DE ALMEIDA MÔNICA COX DE BRITTO PEREIRA

no mundo, com uma população que varia desde centenas a mais de um milhão de pessoas em cada uma delas. No Brasil, 33,6\% da população vive em favelas.

Harvey (2012b) aponta que a geografia burguesa, muito embora aspire à compreensão universal da diversidade da vida social, cultiva frequentemente perspectivas etnocêntricas e paroquiais em relação a essa diversidade, tendo sido, inúmeras vezes, um veículo para a transmissão de doutrinas de superioridade nacional, cultural ou racial. As ideias do destino 'manifesto' ou 'geográfico', da 'missão civilizadora' da burguesia e da 'responsabilidade do homem branco' encontram-se difusas, amplamente, pelo pensamento geográfico. A informação geográfica, como a contida nos mapas, por exemplo, pode ser facilmente utilizada para promover a hostilidade entre os povos, explorar o medo, e, assim, justificar a dominação neocolonial, o imperialismo e a repressão interna - particularmente nas áreas urbanas -.

A própria ideia acerca da promoção e da proteção dos direitos humanos pode ser utilizada pelos atores hegemônicos para 'fazer negócios', através de concepções, flagrantemente, colonialistas e racistas acerca dos direitos humanos. Por isso, pensar os direitos humanos em espaços de injustiça ambiental, tais como as favelas localizadas às margens de rios, requer pensamento crítico, pois o mesmo discurso dos direitos humanos pode tomar a população 'alvo' de tal discurso ou como 'objeto' ou como ‘sujeito' de tais direitos (ALMEIDA, 2014).

O pensamento dominante considera 'democrática' a distribuição dos riscos ambientais, e se atém apenas ao tema do desperdício e da escassez, consagrando, por conseguinte, o mercado como o mecanismo por excelência para regular as questões ambientais. Contra tal corrente, dominante, de pensamento, insurgiram-se os movimentos por justiça ambiental. Tais movimentos redefiniram a questão ambiental, incorporando na questão ambiental articulações com as lutas por justiça social, pois esta era e é uma necessidade sentida pelos movimentos populares de base, que ao se verem diante de situações concretas de enfrentamento percebem que a tutela ambiental que recebem é 'desigual' (ACSERALD; MELLO; BEZERRA, 2009).

Categorias como classe e raça têm demonstrado estar diretamente ligadas à localização dos perigos ambientais (WHITE, 1998). Muito embora a Declaração Universal dos Direitos Humanos afirme que a todos os seres humanos devam ser garantidos os mesmos direitos, em condições de igualdade, independentemente de cor ou classe, a questão racial e a questão da desigualdade de classes têm tido impactos negativos em relação ao respeito devido aos direitos humanos, em termos de exclusão e de desigualdade no acesso a tais direitos, respectivamente.

A injustiça ambiental é incompatível com todo o extenso rol dos direitos humanos. Direitos étnicos, culturais, econômicos, sociais, políticos, ambientais, etc. são vulnerados e/ou 
DIREITOS HUMANOS SOB FOGO CRUZADO: INJUSTIÇA AMBIENTAL, RACISMO, SEXISMO E CLASSES SOCIAIS SÁVIO SILVA DE ALMEIDA MÔNICA COX DE BRITTO PEREIRA

violados em situações de injustiça ambiental. Devido à degradação ambiental localizada nos espaços ocupados por grupos étnicos e raciais, minoritários e pobres, tais grupos frequentemente são representados como 'bodes expiatórios', por excelência, ou seja, tais grupos são culpabilizados pelos males socioambientais, que os mesmo têm de suportar, através dos mesmos mecanismos de exclusão e desigualdade que os oprimem. De acordo com Engels (2015, p. 40):

[...] os trabalhadores são empurrados do dentro das cidades para a periferia, as moradias dos trabalhadores e, de modo geral, as moradias menores se tornam raras e caras e muitas vezes nem podem ser adquiridas, porque nessas condições a indústria da construção civil, para a qual as moradias mais caras representam um campo de especulação muito mais atrativo, apenas excepcionalmente construirá moradias para trabalhadores.

Para Harvey (2012a, p. 329): “O desenvolvimento geográfico desigual deveria ainda ser concebido antes como um direito do que como uma necessidade capitalisticamente imposta que reduz as oportunidades de vida num dado lugar a fim de incrementá-las noutra”. Ou seja, baseando-se na Declaração de Direitos Humanos das Nações Unidas - Artigos 22 e 27 -, David Harvey (2012a) afirma que a ideia de direito ao 'desenvolvimento' deve estar fundada em alguma espécie de base territorial e coletiva. Ao tratar, mais especificamente, do 'direito a um ambiente de vida decente e saudável' Harvey (2012a) aponta que é imperativo o adequado estabelecimento de direitos universais, muito embora seja inequívoco que a interpretação, o significado e a aplicação desses direitos vão envolver grandes dificuldades.

Pensar os direitos humanos requer pensar em como as desigualdades de acesso aos recursos naturais, tais como a terra, implicam em situações que afetam de forma desigual grupos étnico-raciais minoritários, a classe trabalhadora e as Mulheres.

\section{DIREITOS HUMANOS E RACISMO}

Os conceitos de relações raciais e de raça, por um lado, parecem sugerir explicações biológicas e/ou culturalistas dos fenômenos institucionais e sociais; por outro lado, parecem referir-se a formas de vínculo social que, em determinados contextos políticos, competem com as formações de classes. O marxismo analisa a raça como um fator atuante na política que deve voltar-se para as relações entre as situações nas quais se entende estar em jogo 'relações raciais' e o que se pode considerar como relações institucionais com origem na formação de classes. Uma classificação geral da humanidade em raças não é satisfatória para explicar as 
DIREITOS HUMANOS SOB FOGO CRUZADO: INJUSTIÇA AMBIENTAL, RACISMO, SEXISMO E CLASSES SOCIAIS SÁVIO SILVA DE ALMEIDA MÔNICA COX DE BRITTO PEREIRA

diferenças políticas. Os conflitos e as relações raciais são estruturados pelos fatores políticos e econômicos de caráter mais geral (REX, 2012).

Para Schwarcz (2003) a ideologia do racismo científico à brasileira - que surge tardiamente, fundamentando-se em ideologias já desacreditadas, à época, na Europa - conviveu, paradoxalmente, no período entre 1870 e 1930, ao lado de um modelo liberal jurídico na concepção do Estado, que enfrentava a retomada de um debate acerca da questão da igualdade - tendo como base conclusões “deterministas" raciais e um paralelo enfraquecimento da discussão acerca da cidadania. Assim, liberalismo e racismo conviveram no final do século XIX. A afirmação dos direitos humanos e do igualitarismo das luzes convivia com certa ausência dos direitos de cidadania.

Atualmente, o Comitê para a Eliminação da Discriminação Racial, da ONU, afirma que CEDR (2013, p. 11, tradução nossa): “A proliferação do discurso do ódio racista em todas as regiões do mundo segue constituindo um desafio contemporâneo para os direitos humanos". Para Fanon (1980, p. 44): “Numa cultura com racismo, o racista é, pois, normal. A adequação das relações económicas e da ideologia é, nele, perfeita. [...] Ora, é preciso voltar a dizê-lo, todo o grupo colonialista é racista”.

O racismo é uma doutrina de desumanização, de 'coisificação' do ser humano, logo é incompatível com a promoção e a proteção dos direitos humanos. 0 racista busca instituir uma relação de opressão, pois tal doutrina só reconhece o oprimido como uma 'peça', um instrumento de trabalho, uma coisa. É uma doutrina da opressão, nos termos da 'Pedagogia do Oprimido' de Paulo Freire (2005). Para Schwarcz (2013, p. 39):

Desterrados de seu continente, separados de seus laços de relação pessoal, ignorantes da língua e dos costumes, os recém-chegados se transformavam em boçais. Entendido como propriedade, uma peça ou coisa, o escravo perdia sua origem e sua personalidade. Servus non habent personam: "o escravo não tem pessoa", é um sujeito sem corpo, sem antepassados, nomes ou bens próprios.

A ideia de que o 'escravo' não tem pessoa representa uma negação radical dos direitos humanos, uma vez que retira a humanidade presente neste ser humano, caracterizando-o, no máximo, como uma propriedade de outro ser humano. A doutrina do racismo é extremamente perniciosa, exatamente, por negar a humanidade e em consequência negar a dignidade humana, atributo inerente a todo e qualquer ser humano, dignidade esta que representa o núcleo que deve ser protegido pelos direitos humanos. De acordo com Frantz Fanon (2005, p. 61):

Para o povo colonizado, o valor mais essencial, porque mais concreto, é primeiro a terra: a terra que deve garantir o pão e, é claro, a dignidade. Mas essa dignidade não tem nada a ver com a dignidade da "pessoa humana". Dessa 
DIREITOS HUMANOS SOB FOGO CRUZADO: INJUSTICCA AMBIENTAL, RACISMO, SEXISMO E CLASSES SOCIAIS

pessoa humana ideal, ele nunca ouviu falar. 0 que o colonizado viu no seu solo é que se podia impunemente prendê-lo, espancá-lo, esfomeá-lo; e nunca nenhum professor de moral, nunca nenhum padre veio receber as pancadas em seu lugar nem dividir seu pão com ele.

Por isso, para Frantz Fanon (2005, p. 244-245):

0 intelectual colonizado que decide combater as mentiras colonialistas o fará em escala continental. O passado é valorizado. [...] 0 colonialismo, que não matizou os seus esforços, não deixou de afirmar que o negro é um selvagem e o negro, para ele, não era nem o angolano nem o nigeriano. Ele falava a língua negra. Para o colonialismo, esse vasto continente era um antro de selvagens, uma região infestada de superstições e fanatismo, digna de desprezo, carregada de maldições divinas, lugar de antropófagos, lugar de negros. A condenação do colonialismo é continental.

Mas, sendo o colonialismo, um processo de desigualdade de poder e de saber, como lutar para desconstruir tal projeto? Bourdieu (1999, p. 284, tradução nossa) é esclarecedor ao afirmar que:

É na esfera intelectual onde os intelectuais devem levar o combate, não somente porque é sobre este terreno onde suas armas são mais eficazes, senão também porque, a maioria das vezes, é em nome de uma autoridade intelectual - em particular da ciência - que as novas tecnocracias chegam a se impor. Assim, por exemplo, a nova demagogia política se apoia nas pesquisas para legitimar as práticas das políticas neoliberais, as medidas repressivas contra os estrangeiros ou as políticas culturais hostis a vanguarda. Esta é a razão pela qual os intelectuais devem dotar-se de meios de expressão autônomos, independentes dos requerimentos públicos ou privados, e organizar-se coletivamente para pôr suas próprias armas ao serviço dos combates progressistas.

De acordo com o Comitê para Eliminação da Discriminação Racial, da ONU, CEDR (2013): "Dado que o racismo pode ser produto, entre outras coisas, do doutrinamento ou de uma educação inadequada, a educação para a tolerância e os discursos em sentido contrário constituem antídotos especialmente eficazes contra o discurso de ódio racista". Se o colonialismo iniciou-se a partir de um saber colonial, a partir da descolonização da história do colonialismo, tal saber e o seu respectivo sistema de relações sociais, o colonialismo, começarão a ruir.

Porém, não se trata de caridade, mas de reconhecimento e luta por direitos. A história demonstra a aptidão que a humanidade possui para conquistar direitos. Domenico Losurdo (2015) relembra a grande revolução dos Negros liderada por Toussaint L'Ouverture, que pôs em movimento um processo de reação em cadeia da abolição da escravidão. De acordo com James (2010) a colônia francesa das índias Ocidentais de São Domingos, em 1789, representava dois terços do comércio exterior da França e era o maior mercado individual para o tráfico negreiro 
DIREITOS HUMANOS SOB FOGO CRUZADO: INJUSTICCA AMBIENTAL, RACISMO, SEXISMO E CLASSES SOCIAIS SÁVIO SILVA DE ALMEIDA MÔNICA COX DE BRITTO PEREIRA

europeu, possuindo uma estrutura sustentada pelo trabalho de meio milhão de escravos. Em 1971, dois anos após a Revolução Francesa e dos seus reflexos em São Domingos, os escravos se revoltaram. Derrotaram os soldados da monarquia francesa, uma invasão espanhola e uma expedição britânica. Em 1803, a derrota da expedição de Bonaparte resultou no estabelecimento do Estado Negro do Haiti, que permanece até os dias atuais.

Os "senhores" sempre conviveram com uma grande dificuldade, que estava justamente em tentar impor o estado de escravidão aos seres humanos. James (2010, p. 26) é esclarecedor ao afirmar que:

A dificuldade consistia no fato de que, embora fossem apanhados como animais, transportados em cercados, atrelados para trabalhar ao lado de um cavalo ou de um burro sendo ambos feridos pelo mesmo chicote, colocados em estábulos e deixados para morrer de fome, eles permaneciam, apesar de suas peles negras e dos seus cabelos encaracolados, quase irresignavelmente seres humanos; com a inteligência e os rancores dos seres humanos. Para amedrontá-los e torná-los dóceis era necessário um regime de calculada brutalidade e de terrorismo, e é isso o que explica o extraordinário espetáculo de proprietários despreocupados em preservar as suas propriedades: tinham antes de cuidar da própria segurança.

Há de jamais olvidar-se o princípio defendido por Fanon (2008, p. 85): “[...] uma sociedade é racista ou não o é”. Não há sociedades mais ou menos racistas, bem como o racismo não é algo a ser tomado como atitude de indivíduos isolados, mas o racismo é sempre estrutural, fazendo parte ou não das estruturas de uma sociedade, como sustenta Fanon (2008). Ou seja, uma sociedade formada durante mais de 300 anos sob uma base econômica escravocrata/patriarcal e que mesmo após a tal 'abolição' insiste em substituir as 'senzalas' pelas 'favelas' e/ou 'periferias', que insiste em aceitar discriminações de cor, classe e local de moradia como fatores determinantes para o acesso ao mercado de trabalho, o acesso à saúde e à educação, não pode ser uma sociedade estruturalmente livre do racismo. Frantz Fanon (1952) já registrara que a desalienação do Negro implica numa tomada de consciência abrupta das realidades sociais e econômicas. Pois, só após um duplo processo o complexo de inferioridade se havia tornado possível: primeiramente, através da desigualdade econômica e, em seguida, pela interiorização ou, dito de outra forma, a epidermização de tal inferioridade ${ }^{2}$. Para Ana Freire (2012) em grande parte, a classe social no Brasil está relacionada à cor. As Negras e Negros são encarados como seres intrinsecamente inferiores, devido à mentalidade escravocrata ainda vigente. Os dados governamentais, de 2011, segundo a referida autora, apontam o seguinte

\footnotetext{
${ }^{2}$ Frantz Fanon revela com maestria a relação, simultânea, entre a desigualdade econômica e a exclusão, como fundamentos do racismo. Uma, a desigualdade econômica, é o fundamento material do racismo, a outra, a exclusão e a interdição da humanidade do 'colonizado', é o fundamento ideológico do racismo.
} 
perfil da população em condições de miséria ou pobreza absoluta, estimada em 16 milhões de habitantes:

- $59 \%$ destas pessoas estão concentradas na Região Nordeste - 9,6 milhões de pessoas;

- $51 \%$ têm até 19 anos de idade, enquanto 40\% têm até 14 anos de idade;

- $53 \%$ dos domicílios não estão ligados à rede de esgoto ou fossa séptica;

- $26 \%$ são analfabetos - 15 anos ou mais -, cerca de 4 milhões de pessoas;

- $71 \%$ são Negros - pardos e pretos -.

Assim, é importante reconhecer, como o faz Neves (2005) que a luta antirracista perpassa, necessariamente, pelo reconhecimento do grupo social, Negro, tal como o faz o Movimento Negro Unificado, e pela redistribuição das oportunidades sociais, ou seja, pela garantia equânime dos direitos humanos, de caráter civil, político, mas, também, os de caráter social, econômico, cultural, ambiental etc.

0 racismo é uma ideologia que se travestiu de uma pseudo-ciência, porém tal discurso sempre foi vazio de ciência. 0 racismo surgiu com o intuito de legitimar a dominação do homem branco, escreve-se homem, pois se deseja enfatizar que ao lado do racismo, ainda hoje, caminham o patriarcado, o antissemitismo, etc.

\section{DIREITOS HUMANOS E SEXISMO}

A ciência moderna é apresentada como um sistema neutro de consciência universal, que desqualificou todos os demais sistemas de conhecimentos e crenças por sua neutralidade e universalidade em matéria de valores, e pela 'lógica’ do seu método para chegar a afirmações objetivas acerca da natureza. Porém, o saber feminino tem reconhecido que esta ciência representa, em realidade, um projeto patriarcal e masculino que carrega em si o subjulgamento da Mulher e da Natureza. Tal projeto é representado, claramente, por Francis Bacon, que foi considerado pai da ciência, ao fazer coincidir a ciência, o poder e o conhecimento humano, em benefício do empresário europeu da classe média. O seu método 'experimental' era profundamente dicotômico: promovia a dominação masculina sobre a Mulher, a Natureza e o não ocidental. Para Bacon, a natureza já não era a Mãe-Natureza, mas apenas uma natureza fêmea, conquistada pela mentalidade masculina agressiva. Para dominar a Natureza e a Feminilidade se associaram a ciência e a masculinidade, assim as ideologias do gênero e da ciência se reforçam, simultaneamente (SHIVA, 1995). 
DIREITOS HUMANOS SOB FOGO CRUZADO: INJUSTIÇA AMBIENTAL, RACISMO, SEXISMO E CLASSES SOCIAIS SÁVIO SILVA DE ALMEIDA MÔNICA COX DE BRITTO PEREIRA

As Mulheres têm sido colonizadas desde o início do Estado-nação moderno - as pátrias -. 0 Estado-nação controlou a sua sexualidade, a sua fertilidade, a sua força laboral e a sua capacidade de trabalho. Sem esta colonização, nem o moderno Estado-nação nem o capitalismo poderiam ser sustentados. Tal colonização é o que constitui o fundamento do que hoje se designada por 'sociedade civil'. A tarefa do Estado-nação moderno é exercer uma mediação entre os direitos humanos universalmente declarados, segundo os quais todas as pessoas são livres e iguais, e os segmentos populacionais desiguais de fato, das diferentes colônias internas e externas: entre cidadãos e estrangeiros; entre Mulheres e homens; entre trabalhadores não assalariados e trabalhadores assalariados; entre a maioria e minorias raciais e étnicas (MIES, 1993b).

A sociedade patriarcal-capitalista industrial baseia-se em dicotomias fundamentais entre Natureza e Homem, Mulher e Homem, Aldeia e Cidade, Colônias e Metrópoles, Vida e Trabalho, Cultura e Natureza, etc. Tais dicotomias são, na verdade, 'colonizações'. O desejo de uma destas partes - a Natureza, a Mulher, a Aldeia, as Colônias, a Vida, a Cultura, etc. - tem de ser sentimentalizado; tais partes têm de ser romantizadas e, simultaneamente, acrescentadas ao paradigma moderno existente. Omite-se desse discurso da modernidade a violência estrutural e direta que recai sobre a Mulher, a Natureza e outras partes colonizadas que são separadas do todo, transformadas, assim, em 'outro' (MIES, 1993C).

Dentre os habitantes mais pobres do planeta $70 \%$ são Mulheres - incluindo-se em tal número as meninas - as quais, junto com as crianças, representam o setor mais marginal em um mundo dominado pelos homens. As Mulheres ocupam apenas $5 \%$ dos postos de maior hierarquia nas grandes corporações e se encontram praticamente excluídas das instâncias de decisão internacional em matéria econômica; ou seja, a presença das Mulheres nos grandes centros de tomada de decisão, e que conduzem a ordem mundial vigente, é quase que acidental. Situação como a descrita está presente, também, nas Nações Unidas e nos organismos internacionais relacionados à proteção e defesa dos direitos humanos (PEDROZA, 2009).

Muito embora, sob o regime capitalista de produção, exista uma 'promessa' em torno da libertação da Mulher, em termos de igualdade de direitos e de igualdade de condições no mercado de trabalho, no acesso à educação, etc., tal promessa não se cumpriu, de fato. À Mulher, sobretudo à Mulher Negra, cabe um status de inferiorização na hierarquização de gênero, de raça e de classe, sob o sistema capitalista de produção. Seria necessário, assim, buscar novas formas de se pensar as instituições e a legalidade, pois mesmo sob o sistema comunista que existiu de fato, na Rússia, à Mulher cabia um status 'inferior' em relação ao 
DIREITOS HUMANOS SOB FOGO CRUZADO: INJUSTICCA AMBIENTAL, RACISMO, SEXISMO E CLASSES SOCIAIS SÁVIO SILVA DE ALMEIDA MÔNICA COX DE BRITTO PEREIRA

homem. O que não inválida que a efetiva liberação da Mulher Negra se dê através do comunismo, desde que repensado em suas instituições e legalidade, pois a revolução econômica, que iguala as classes, deve ser acompanhada por uma revolução política, para que haja representação política dos grupos sociais que atualmente são minoritários (DAVIS, 2000). E ainda acrescenta Erich Fromm (2009, p. 150, tradução nossa) que: “O radicalismo político, sem genuíno radicalismo humano, não levará além do desastre”.

De acordo com Vandana Shiva (1993, p. 117):

Para colocar as mulheres e as crianças em primeiro lugar é necessário, acima de tudo, uma inversão da lógica que tem tratado as mulheres como subordinadas por criarem vida, enquanto os homens são superiores por a destruírem. Todas as realizações passadas do patriarcado têm-se baseado na alienação da vida e conduzido ao empobreciemnto das mulheres, das crianças e do ambiente. Se quisermos inverter este declínio, a criação, ao contrário da destruição da vida, deve ser vista na nossa capacidade para reconhecer, respeitar e proteger o direito à vida de todas as espécies variadas do mundo.

A Declaração Universal dos Direitos Humanos - artigos 1 a 10 -, de 1948, da ONU, insiste no direito à dignidade e integridade da pessoa política e do corpo. Assim, supõe-se o direito de estar livre de assassinatos, prisões, torturas e outras coerções físicas, que no passado foram frequentemente aplicados com a finalidade de alcançar objetivos políticos. Deve estar, também, na base dessa concepção o direito das Mulheres de viver livres de coerções, da violência cultural, institucionalizada e doméstica - e ao controle das suas próprias funções reprodutivas. A violência contra as Mulheres e sua subserviência a sistemas paternalistas e patriarcais de dominação tornou-se uma importante questão com respeito à qual são profundamente prementes e plausíveis reivindicações de direitos universais (HARVEY, 2012a). Porém, as Mulheres, desde os anos 1950 e 1960, foram protagonistas de um conjunto de lutas que afirmavam o desejo, a subjetividade e as novas sensibilidades (PORTO-GONÇALVES, 2013). De acordo com Porto-Gonçalves (2013, p. 151-152):

As mulheres foram às ruas condenar o machismo que atravessava ideologias, geografias e histórias. Trouxeram para o plano público uma sensibilidade que, antes, ficara restrita ao plano familiar, privado, pelo menos no mundo ocidental. Afinal, na melhor tradição grega, homem público tem uma conotação positiva e mulher pública uma conotação negativa - prostituta.

As doutrinas sexistas, também, representam a interdição dos direitos humanos às Mulheres, tendo em vista que o mercado de trabalho, bem como a representação política da Mulher tem sido tolhida através da 'naturalização' da divisão sexual do trabalho. Tal divisão é expressa na divisão entre trabalho assalariado, fora de casa, como sendo 'naturalmente' 
DIREITOS HUMANOS SOB FOGO CRUZADO: INJUSTIÇA AMBIENTAL, RACISMO, SEXISMO E CLASSES SOCIAIS SÁVIO SILVA DE ALMEIDA MÔNICA COX DE BRITTO PEREIRA

responsabilidade do 'homem', e trabalho doméstico, este que seria uma responsabilidade 'natural' da Mulher. Tal processo alimenta a 'feminização da pobreza' e a consequente 'violência estrutural' sofrida pelas Mulheres e Meninas, sob o jugo das sociedades estruturalmente patriarcais, sejam elas capitalistas e/ou socialistas.

\section{DESIGUALDADE DE CLASSES, DIREITOS DESIGUAIS}

É impactante a afirmativa de Karl Marx (2013, p. 364) segundo a qual a: “[...] exploração da força de trabalho é o primeiro direito humano do capital". Tal afirmação está fundada na noção de que o direito, na sociedade capitalista, faz parte da superestrutura ideológica que 'legitima' a estrutura capitalista da base de produção econômica. No mesmo sentido, Karl Marx (2010, p. 149) afirma que: “O economista nacional - tão bem quanto a política nos seus direitos humanos - reduz tudo ao homem, isto é, ao indivíduo, do qual retira toda determinidade, para o fixar como capitalista ou trabalhador". De acordo com Harvey (2014) Karl Marx ataca em O Capital a ideia de que exista uma noção abstrata, ideal de justiça fora das relações sociais existentes.

A “preocupação" neoliberal com os indivíduos põe em segundo plano toda a preocupação, própria das democracias sociais, com a democracia, a igualdade e as solidariedades sociais. Os tribunais são moldados para atuar na defesa dos interesses das classes dominantes, favorecendo assim os direitos de taxa de lucro e de propriedade privada em detrimento dos direitos à justiça social e à igualdade. Viver sob o neoliberalismo significa submeter-se a um conjunto de direitos necessários à acumulação do capital. Os direitos inalienáveis à taxa de lucro e à propriedade privada se sobrepõem a quaisquer outras concepções possíveis de direitos, também, inalienáveis (HARVEY, 2012c). De acordo com Harvey (2014, p, 183): “A justiça está inserida nas relações sociais de um dado modo de produção (a teoria liberal da justiça, portanto, deriva da ascensão do capital ao predomínio nas relações sociais)".

De acordo com Harvey (2012c, p. 195):

Não obstante, não são esses os únicos direitos que temos à disposição. Mesmo na concepção liberal expressa na Carta da Organização das Nações Unidas há direitos derivados, como liberdade de manifestação e de expressão, de educação e segurança econômica, direitos de organizar sindicatos e assim por diante. Fazer que esses direitos tenham pleno vigor constituiria um enorme problema para o neoliberalismo. Tornar primários esses direitos hoje derivados e tornar derivados 
DIREITOS HUMANOS SOB FOGO CRUZADO: INJUSTICCA AMBIENTAL, RACISMO, SEXISMO E CLASSES SOCIAIS

os direitos hoje primários à propriedade privada e à taxa de lucros implicaria uma revolução de enorme relevância para as práticas político-econômicas. Também há concepções inteiramente distintas de direitos a que podemos apelar - de acesso aos bens comuns globais ou à segurança básica de alimentação, por exemplo. "Entre dois direitos, quem decide é a força." As lutas políticas em torno da concepção de direitos adequada, e mesmo da própria liberdade, passam ao primeiro plano na busca de alternativas.

O colonialismo, por sua vez, não está ultrapassado, muito pelo contrário, ele está contido na lógica do capitalismo. A economia política capitalista ao apropriar-se do discurso dos direitos humanos visa legitimar o enquadramento da história no modelo societal liberal sem peias, ou seja, aceitar o capitalismo significa aceitar o "fim da história" como o pretende Fukuyama (1999). Tal discurso afirma, formalmente, a igualdade, a liberdade e a fraternidade - princípios que fundam os direitos humanos desde a Revolução Francesa, de 1789 - ao mesmo tempo em que legitima, em nome da propriedade e do lucro, a divisão social em classes sociais extremamente desiguais, as formas "ocultas" de racismo, sexismo, xenofobia, genocídio etc. Conforme aponta Gilles d’Elia (2008) apud Laske (2008, tradução nossa, grifo nosso):

“A Europa é indefensável”: estas três palavras, que abrem o Discours sur Le
Colonialisme de Aimé Cesaire, são um veneno perigoso para os escribas do poder.
Pois nós sabemos atualmente que o último momento do da colonização
consiste em colonizar a história do colonialismo. Mesmo quando os colonos se
forem, tudo restará a ser feito. Pois a colonização não é um fenômeno singular,
um acidente infeliz da nobre história ocidental, ele é a consequência de um
regime político preciso: o capitalismo. E enquanto este regime estiver de pé, ele
jamais poderá contar a verdadeira história do colonialismo, pois ele se
condenaria no mesmo golpe.

As concepções 'coloniais' acerca da 'Natureza', da 'Mulher', do 'Negro(a)', são, também, concepções hierárquicas que são influenciadas pelo regime capitalista de produção, mas que, simultaneamente, reforçam e influenciam o capitalismo. Romper com essas concepções 'coloniais', e, por conseguinte, garantir a igualdade de direitos, de fato, implicaria numa revolução no seio da economia política capitalista, que não poderia sustentar-se após tal revolução. A igualdade de direitos, de fato, implicaria na realização, simultânea, da democracia política, econômica, social, de gênero e racial, implicando, assim, no reconhecimento das identidades - raciais e de gênero - e na distribuição de poder - político, econômico e social entre os diversos grupos sociais. 


\section{CONCLUSÃO}

Proteger a dignidade inerente a todo ser humano significa reconhecer e respeitar os direitos de todos os seres humanos, independentemente de suas diferenças étnico-raciais e de gênero e das desigualdades que os oprimem, o que pode implicar também no engajamento na luta pelos direitos humanos. Tal reconhecimento pode exigir mudanças nas relações intrapessoais, mas também mudanças nas relações interpessoais, pois, para que os direitos humanos sejam efetivamente promovidos, necessário se faz que haja um projeto político que coloque o cumprimento dos deveres impostos pela cidadania como fundamento da promoção dos direitos humanos.

As desigualdades ambientais, como a injustiça ambiental, têm afetado de forma desproporcional os grupos étnico-raciais minoritários, a classe trabalhadora e as Mulheres. 0 racismo funciona legitimando processos de desigualdade econômica e de desigualdade no acesso às oportunidades, implicando no complexo de inferioridade, como sustenta Frantz Fanon. Porém, os processos de desigualdade econômica e de desigualdade no acesso às oportunidades, também, afetam de forma negativa as Mulheres, através da ideologia sexista. As desigualdades de classes, por sua vez, alimentam e são alimentadas pelos processos descritos.

Por isso, a leitura dos direitos humanos deve ser feita paralelamente à leitura das realidades sócio-históricas concretas. Pensar os direitos humanos requer pensamento crítico, pois as mesmas doutrinas acerca da igualdade, liberdade e fraternidade, conviveram e convivem, ao longo da história, com práticas racistas, sexistas e classistas, paradoxalmente, contrárias a tais doutrinas. Se por um lado a exclusão reproduz as hierarquias sociais, por outro lado a desigualdade reproduz as classes sociais; exclusão e desigualdade não se excluem, mas, muito pelo contrário, complementam-se no processo de aniquilação da humanidade. As desigualdades de gênero, de raça e de classes e a injustiça ambiental são construções sociais que se alinham para o enfraquecimento da relevância da construção socio-histórica dos direitos humanos. 


\section{REFERÊNCIAS}

ACSERALD, H.; MELLO, C. C. do A.; BEZERRA, G. das N. O que é Justiça Ambiental. Rio de Janeiro: Garamond, 2009.

ALMEIDA, S. S. de. Direitos Humanos e Justiça Ambiental em Comunidades Perifluviais Urbanas. 202 f., 2014. Dissertação (Mestrado em Desenvolvimento e Meio Ambiente). Universidade Federal de Pernambuco - Centro de Filosofia e Ciência Humanas. Recife, 2014.

BERRY, K. A. Race for Water? Native Americans, Eurocentrism, and Western Water Policy. In: CAMACHO, D. E. Environmental Injustices, Political Struggles: Race, Class, and the Environment. Durham-London: Duke University Press, 1998.

BOURDIEU, P. Postfacio. 1999. In: BOURDIEU, P. Intelectuales, política y poder. Madrid: Clave Intelectual, 2012.

CERD. Recomendación general $N^{\circ}$ 35. La lucha contra el discurso de odio racista. 2013. Disponível em: < http: / /docstore.ohchr.org/SelfServices/FilesHandler.ashx?enc=6QkG1d \%2fPPRiCAqhKb7yhssyNNtgl51ma08CMa6o7Bglz8iG4SuOjovEP\%2bcqr8joDQWqe7tgHamAOAPSeR0m 5BxrCnsm0V3KTa996NqzxH9\%2bl9Jb5mz6RLoeBbbW3AhVl>. Acesso em: 27/04/2014.

DAVIS, A. Y. Women and Capitalism: Dialectics of Oppression and Liberation. In: JAMES, J.; SHARPLEY-WHITING, T. D. (Editors). The Black Feminist Reader. Malden-Oxford: BLACKWELL, 2000.

DAVIS, M. Planeta favela. São Paulo: Boitempo, 2006.

DEMO, P. Introdução à sociologia: Complexidade, Interdisciplinaridade e Desigualdade Social. São Paulo: Atlas, 2009.

ENGELS, F. Sobre a Questão da Moradia. São Paulo: Boitempo, 2015.

ENGELS, F.; KAUTSKY, K. O Socialismo Jurídico. 2 ed. São Paulo: Boitempo, 2012.

FANON, F. Peau Noire, Masques Blancs. Paris: Éditions du Seuil, 1952.

. Em Defesa da Revolução Africana. Lisboa: Sá da Costa, 1980.

. Os Condenados da Terra. Juiz de Fora: Ed. UFJF, 2005.

Pele Negra, Máscaras Brancas. Salvador: EDUFBA, 2008.

FERNANDES, F. A Integração do Negro na Sociedade de Classes. Vol. 1. São Paulo: Editora Globo, 2008. 


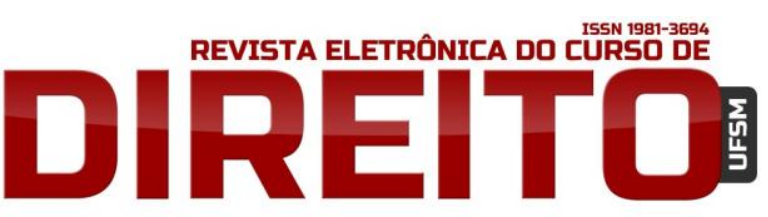

DIREITOS HUMANOS SOB FOGO CRUZADO: INJUSTIÇA AMBIENTAL, RACISMO, SEXISMO E CLASSES SOCIAIS

SÁVIO SILVA DE ALMEIDA MÔNICA COX DE BRITTO PEREIRA

FREIRE, A. M. A. Introdução. In: FREIRE, P. À Sombra desta Mangueira. Rio de Janeiro:

Civilização Brasileira, 2012.

FREIRE, P. Pedagogia do Oprimido. Rio de Janeiro: Paz e Terra, 2005.

FROMM, E. Lo Inconsciente Social. Barcelona: Paidós, 2009.

FUKUYAMA, F. O Fim da História e o Último Homem. São Paulo: Gradiva, 1999.

HAESBAERT, R.; PORTO-GONÇALVES, C. W. A Nova Des-Ordem Mundial. São Paulo: Editora UNESP, 2006.

HARVEY, D. Social Justice and the City. Athens-Georgia: The University of Georgia Press, 2009. . O Enigma do Capital: e as Crises do Capitalismo. São Paulo: Boitempo, 2011.

. Espaços de Esperança. 5 ed. São Paulo: Edições Loyola, 2012a.

- Geografia. In: BOTTOMORE, T. (Editor). Dicionário do Pensamento Marxista. 2 ed. Rio de Janeiro: Zahar, 2012b.

. O Neoliberalismo: História e Implicações. 3 ed. São Paulo: Edições Loyola, 2012c.

. Os Limites do Capital. São Paulo: Boitempo, 2013.

. Para Entender o Capital: Livros II e III. São Paulo: Boitempo, 2014.

HUNT, L. A Invenção dos Direitos Humanos: Uma História. São Paulo: Companhia das Letras, 2009.

JAMES, C. L. R. Os Jacobinos Negros: Toussaint L'Ouverture e a Revolução de São Domingos. São Paulo: Boitempo, 2010.

LASKE, K. Sarkozy, l'anti-Césaire. Liberátion : contre-journal, 2008. Disponível em : <http ://www.liberation.fr/contre-journal/2008/04/21/sarkozy-l-anti-cesaire_70091>. Acesso em: 08/04/2014.

LOSURDO, D. Marx, a tradição liberal e a construção histórica do conceito universal de homem. Revista Educação e Sociedade, Campinas, ano 29, nº 57, 1996.

. A Luta de Classes: Uma História Política e Filosófica. São Paulo: Boitempo, 2015.

MARX, K. Manuscritos econômico-filosóficos. São Paulo: Boitempo, 2010.

O Capital: Crítica da Economia Política: Livro I: O Processo de Produção do Capital. São Paulo: Boitempo, 2013.

MARX, K.; ENGELS, F. Manifesto do Partido Comunista. São Paulo: Lafonte, 2012. 
DIREITOS HUMANOS SOB FOGO CRUZADO: INJUSTIÇA AMBIENTAL, RACISMO, SEXISMO E CLASSES SOCIAIS SÁVIO SILVA DE ALMEIDA MÔNICA COX DE BRITTO PEREIRA

MIES, M. Novas Tecnologias Reprodutivas: Implicações Sexistas e Racistas. In: MIES, M.; SHIVA, V. Ecofeminismo. Lisboa: Instituto Piaget, 1993a.

MIES, M. As Mulheres não têm Pátria. In: MIES, M.; SHIVA, V. Ecofeminismo. Lisboa: Instituto Piaget, 1993b.

. O Dilema do Homem Branco: a Procura do que Deve ser Destruído. In: MIES, M.;

SHIVA, V. Ecofeminismo. Lisboa: Instituto Piaget, 1993c.

NEVES, P. S. das. Luta Anti-Racista: Entre Reconhecimento e Redistribuição. Revista Brasileira de Ciências Sociais, vol. 20, n 59, out. 2005.

PEDROZA, B. Privatización y Globalización: Derechos Humanos de las Mujeres. In: GIRÓN, A. (Coord.). Género y Globalización. Buenos Aires: CLACSO, 2009.

PORTO-GONÇALVES, C. W. A Globalização da Natureza e a Natureza da Globalização. 5 ed. Rio de Janeiro: Civilização Brasileira, 2013.

QUIJANO, A. Colonialidade do Poder, Eurocentrismo e América Latina. In: CLACSO (Editorial). A Colonialidade do Saber: eurocentrismo e ciências sociais. Perspectivas latino-americanas. Buenos Aires: CLACSO, 2005.

REX, J. Raça. In: BOTTOMORE, T. (Editor). Dicionário do Pensamento Marxista. 2 ed. Rio de Janeiro: Zahar, 2012.

SANTOS, B. de S. Os direitos humanos na zona de contato entre globalizações rivais. Revista de Direito Constitucional e Internacional. RDCI 64/313. Jul.-set./2008. In: PIOVESAN, F.; GARCIA, M. (Org.). Teoria geral dos direitos humanos. São Paulo: Editora Revista dos Tribunais, 2011. (Coleção doutrinas essenciais; v. 1).

Cortez, 2010.

A Gramática do Tempo: Para Uma Nova Cultura Política. 3 ed. São Paulo:

Direitos Humanos, Democracia e Desenvolvimento. In: SANTOS, B. de S.;

CHAUI, M. Direitos Humanos, Democracia e Desenvolvimento. São Paulo: Cortez, 2013.

SCHWARCZ, L. M. O Espetáculo das Raças: Cientistas, Instituições e Questão Racial no Brasil 1870-1930. São Paulo: Companhia das Letras, 1993. . Racismo no Brasil. 2 ed. São Paulo: Publifolha, 2013.

SHIVA, V. O Empobrecimento do Ambiente: As Mulheres e as Crianças Para o Fim. In: MIES, M.; SHIVA, V. Ecofeminismo. Lisboa: Instituto Piaget, 1993c.

. Abrazar La Vida. Mujer, Ecología y Desarrollo. Madrid: Horas y Horas, 1995. Monoculturas da mente: perspectivas da biodiversidade e da biotecnologia. São

Paulo: Gaia, 2003. 
ISSN 1981-3694

(DOI): $10.5902 / 1981369416052$

REVISTA ELETRÔNICA DO CURSD DE

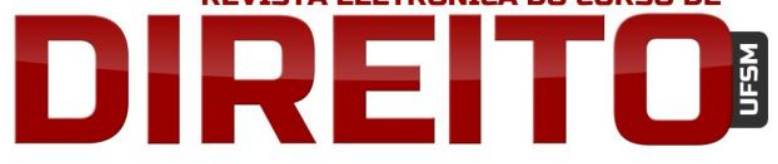

DIREITOS HUMANOS SOB FOGO CRUZADO: INJUSTIÇA AMBIENTAL, RACISMO, SEXISMO E CLASSES SOCIAIS

SÁVIO SILVA DE ALMEIDA MÔNICA COX DE BRITTO PEREIRA

TRINDADE, J. D. de L. Os Direitos Humanos na Perspectiva de Marx e Engels: Emancipação Política e Emancipação Humana. São Paulo: Editora Alfa-Omega, 2011.

WHITE, H. L. Race, Class, and the Environmental Hazards. In: CAMACHO, D. E. Environmental Injustices, Political Struggles: Race, Class, and the Environment. Durham-London: Duke University Press, 1998.

Recebido em: 02/11/2014 / Revisões requeridas em: 25/05/2015 / Aprovado em: 26/10/2015 